\title{
Community diagnosis of physical growth of infants based on monitoring in a routine preventive service
}

\author{
HAVA PALTI, BELA ADLER, ZVI SHAMIR, AND SIDNEY L. KARK \\ From the Department of Social Medicine, the Hebrew University Hadassah Medical School and Hadassah \\ Medical Organisation
}

SUMMARY The physical growth pattern of infants aged from one month to two years was studied in a lower middle class community in Jerusalem. Weight and length were measured at one month and at three, six, 12, and 24 months. In each age and sex group there were at least 200 children. At one month and 24 months the percentage of children below the 10th percentile for weight and also for length was higher than expected, although severely impaired linear growth was observed in only $0.5 \%$ of males and $1.3 \%$ of females at 24 months. The percentage of overweight infants was highest at three months $(6 \cdot 2 \%$ of males and $5 \cdot 2 \%$ females). In the light of these findings, we discuss the feasibility of accurate monitoring of physical growth in maternal and child health clinics; the possibility of an association between maternal stature and the high percentage of children below the 10th percentile for length; and the association between food intake and growth pattern.

Surveillance of physical growth has been made an integral part of the mother and child health services of the Department of Social Medicine, serving a defined neighbourhood of the city of Jerusalem (Kark, 1974). The aim of this surveillance is to assess the growth pattern of the population of children through collection of anthropometric measurements by standardised technique.

The purpose of this paper is to present the growth pattern from one month to two years of age and to assess the nutritional status of this population. For this, reference was made to the National Center of Health Statistics growth charts constructed recently, based on a sample of the child population of the United States of America (National Center for Health Statistics, 1976b; 1977).

Previous reports of studies of physical growth of Israeli children were concerned with the newborn (Handlesman and Davies, 1975; Palti et al., 1977); with infants at twelve months of age (Nichaman and Reshef, 1978); and with schoolchildren (Shiloh and Yekutiel, 1958; Nichaman and Reshef, 1978). The studies were observations of selected groups of children at one time and none of them described a total community at various ages.

\section{Material and methods}

The surveillance was carried out in Kiryat Yovel, a neighbourhood in the western part of Jerusalem. The population of the neighbourhood is entirely Jewish. Fifty-seven per cent of the women of childbearing age are immigrants who came to Israel after the establishment of the State of Israel in 1948. Forty-three per cent are from Asia and North Africa, $14 \%$ from Europe and America, and $43 \%$ of mothers were born in Israel. The social class distribution of the children by fathers' occupations is $31 \%$ in Social Classes I and II (upper); $29 \%$ in $\mathrm{III}_{2}$ (white collar or clerical); $30 \%$ in $\mathrm{III}_{3}$ (blue collar or skilled manual); and $10 \%$ in IV and V (lower). The social class scale is an adaptation of the one used by the British Registrar General for many years (Kark et al., 1964).

All babies born to families living in the defined neighbourhood, or babies of families who moved into the area, are included in the surveillance. This report is concerned with children born during the two-year period 1st June 1971 to 31st May 1973, at different ages in the first two years of their lives. During that period the total number of children was 765 , of whom 379 were males and 386 females. The permissible age 
range for examination at one month was defined as minus one, plus two weeks; at three and six months it was \pm 2 weeks; at 12 months \pm 4 weeks; and at 24 months \pm 10 weeks. The median age at examination was 4.0 weeks at one month, 12.8 weeks at three months, 25.8 weeks at six months, 52.7 weeks at 12 months, and 104.5 weeks at 24 months. The percentage of low-birthweight babies $(2500 \mathrm{~g}$ and below) was $8.1 \%$ and the twinning rate $1 \%$. There was a decline in the number of children aged from one month to two years because of population mobility, and the proportion of children who were examined also declined, from $90 \%$ at one month to $69 \%$ at two years (Table 1). This was because attendance at clinics tends to decline as children grow older; or the infants attending were outside the permissible age range for surveillance.

Weight and length were measured by specially trained public health nurses. Intra- and inter-observer variation was checked. Standard equipment as used in international growth studies was introduced (Falkner, 1960). Weights were recorded to an accuracy of $0.01 \mathrm{~kg}$. Crown heel length was measured as described by Falkner (1960). Length was recorded to an accuracy of $0.1 \mathrm{~cm}$. The National Center for Health Statistics weight and length percentiles (National Center for Health Statistics, 1977) were interpolated by us into weekly age intervals and into 10 percentile categories. On the basis of these tables the percentile for each weight and length measurement was calculated. Age-independent weight-by-length percentiles were also calculated. The reference median of height for age and weight by length was calculated as a percentage of the median. Only the extreme categories were calculated, $90 \%$ or less of the median length by age indicating stunted growth, $80 \%$ or less of weight by length indicating wasting, and above $120 \%$ of weight by length indicating overweight (Nichaman and Reshef, 1978). The presentation of the histograms follows the recommendations of Waterlow et al. (1977).

\section{Results}

Fig. 1 shows the percentage distribution of weight for age percentiles at one, three, six, 12 and 24 months of age by sex. The broken line indicates the expected frequency according to the reference population ( $10 \%$ of the population in each 10 -centile category).

The distribution of attained weight at one month is significantly less than the reference population, for males especially, whereas at three months of age considerably fewer children than expected are below the 10th percentile (males $6 \%$, females $4 \%$ ). At subsequent ages, six, 12, and 24 months, the

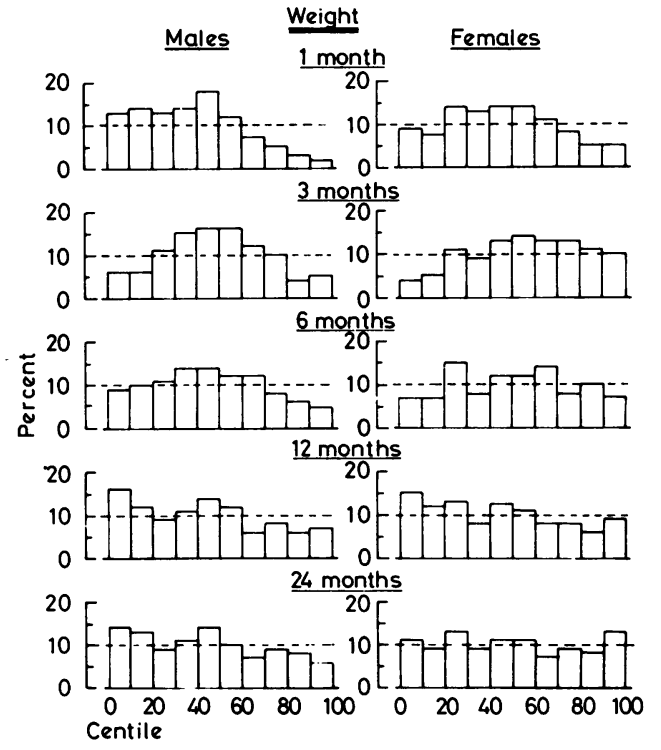

Fig. 1 Percentage distribution of weight for age percentiles.

percentage of low weight infants increases; at 12 months $16 \%$ of males and $14 \%$ of females are below the 10 th percentile. The percentage of infants above the 90th centile is less than expected at all ages for males, and at one, six, and 12 months for females.

Fig. 2 shows the percentage distribution of length for age by sex. The distribution of attained length of

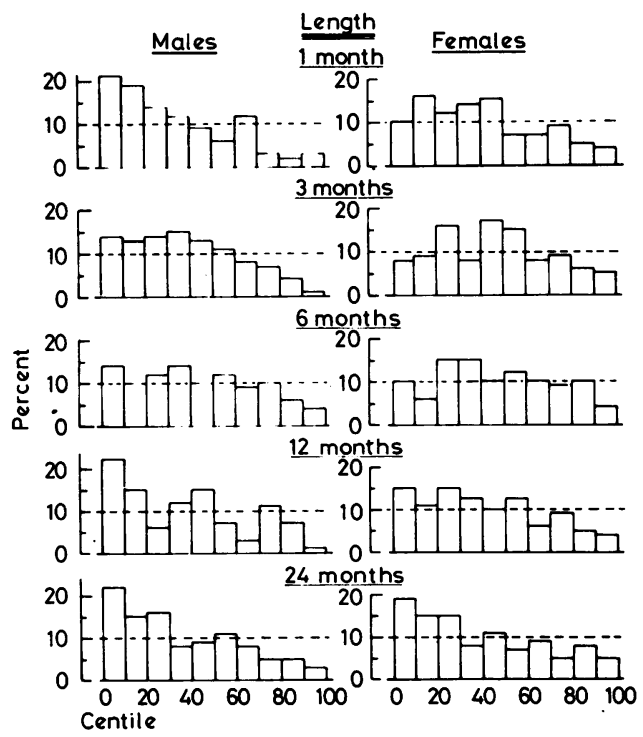

Fig. 2 Percentage distribution of length for age percentiles. 
Table 1 Study population: number and percentages of children examined by age and sex

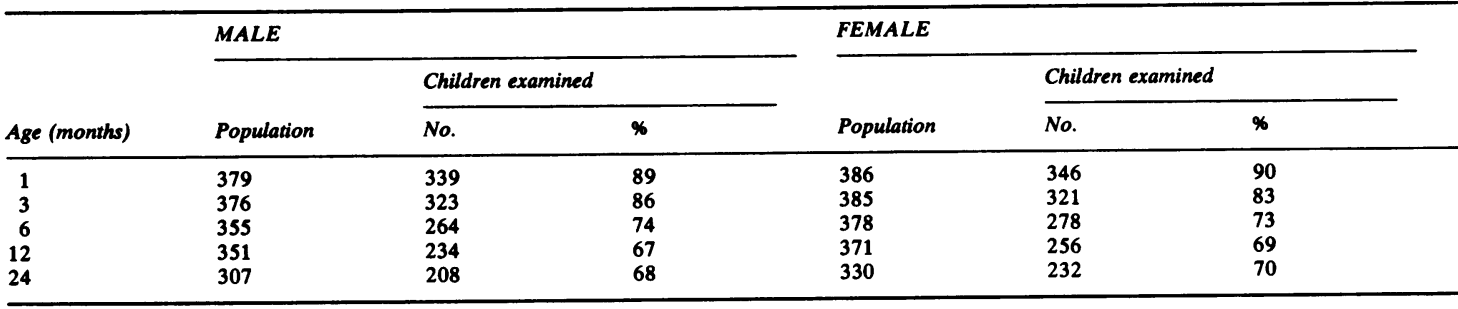

Table 2 Percentage of infants stunted, wasted, or overweight at three, six, 12 and 24 months of age by sex

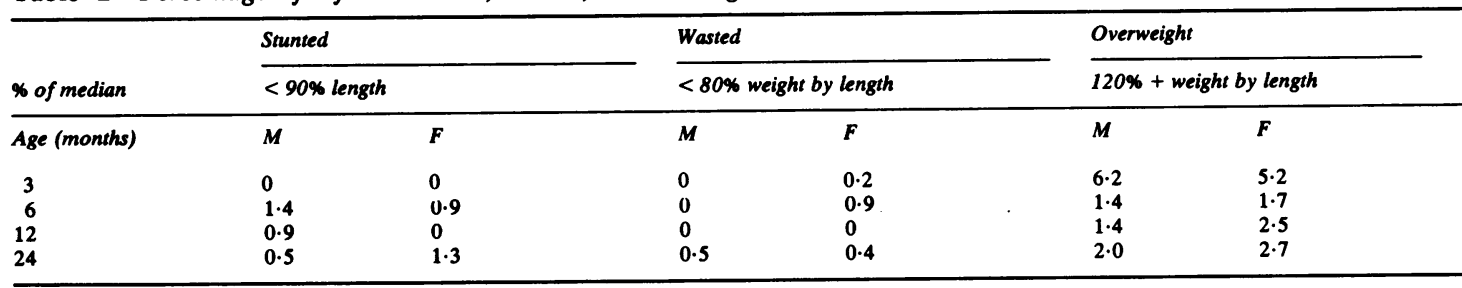

this Jerusalem population of infants at one month is significantly less than that of the reference population. The difference is more pronounced for males than for females. At three and six months the distribution of attained length is similar to that of the reference population. At 12 and at 24 months a high proportion of children fall below the 10 th percentile ( $22 \%$ of males and $19 \%$ of females). Severely impaired linear growth (that is, stunted growth defined as $90 \%$ or less of the medium length for age) was observed in $0-1.4 \%$ males and $0-1.3 \%$ females (Table 2). There are fewer children than expected above the 90th centile for length, at all ages and of both sexes (males $1-4 \%$, females $3-5 \%$ ).

The distribution indicates that both sex groups are light for length at one month of age; at three and six months a considerable shift above the 50th centile is observed (Fig. 3). The percentage of those overweight at three months $(+120 \%$ of median weight by length) is $6 \cdot 2 \%$ for males and $5 \cdot 2 \%$ for females. At subsequent ages the proportion of overweight children decreased (males 1.4-2\%, females $1 \cdot 7-2 \cdot 7 \%$ ) (Table 2 ). Severe wasting (less than $80 \%$ of median weight by length) was rare: $0-0.5 \%$ in males and $0-0.9 \%$ in females.

\section{Discussion}

The surveillance of our study population was built into the routine of the mother and child health services. Our experience since 1971 allows us to conclude that community surveillance of physical

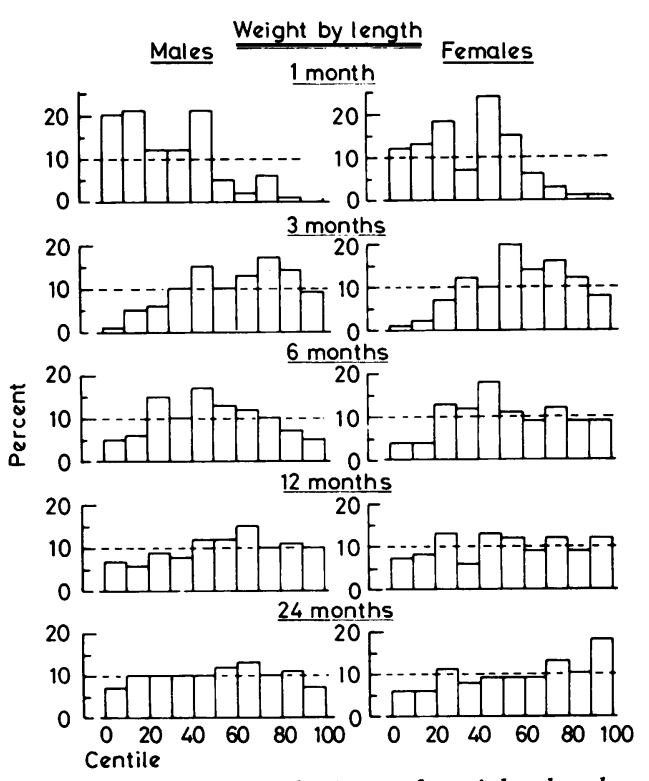

Fig. 3 Percentage distribution of weight by length percentiles.

growth is feasible in a primary child health care service. However, it requires standardisation of methods of follow-up, measurements, and records. The results of this study are based on this inbuilt surveillance. Adequate size of the study population, at least 200 children in each age and sex group, and 
similarity of procedures to those used for the reference population, allow for comparison of this group of children in Jerusalem with the reference population in the growth charts of the National Center for Health Statistics, recommended as a standard for international comparisons of physical growth of children and assessment of the nutritional state of population groups (Waterlow et al., 1977).

The comparison with the reference population indicates that the pattern of weight growth in our study population is somewhat different. The infants are lighter at one month, whereas at three months there are less than the expected percentages of infants below the 10 th percentile or the 50th centile. The same trend is observed in the weight-by-length distribution. At one month, the infants are light for length, whereas at three and six months they become heavy for length. The prevalence of overweight was $5 \cdot 2 \%$ for males and $6 \cdot 2 \%$ for females. The infant population of this community is mainly artificially fed. At three months, only $13 \%$ are breast-fed, $1 \%$ of them exclusively (Palti et al., 1977). The excessive weight gain from one month to three months is possibly due to overfeeding with milk and cereals. In England (Taitz, 1971) and Sweden (Sveger et al., 1975) even higher percentages of the overweight and obese were observed in artificially fed infants at three months. At 12 and 24 months the percentage of infants who were light in weight was greater that at three and six months. The reduction in the numbers of overweight infants at these ages is possibly due to their own ability to regulate food intake and thereby avoid overfeeding by excess intake through bottle-feeding. Although the percentage of infants of light weight increased, wasting, defined as less than $80 \%$ of median weight by length, is not a problem in this population during the first two years of life. The infants of this community are shorter than the reference population at all ages observed, but the percentage of children stunted (less than $90 \%$ of median length for age, indicating chronic malnutrition) is very small $(0-1 \cdot 4 \%)$. In a previous study of a sample of the same children we have shown that dietary intake was adequate for all ages from six to 24 months (Palti et al., 1977). If nutritional intake is adequate and infection rate is similar in this community (Palti et al., 1979) to that in other healthy infant populations (Monto, 1974) possible genetic and other maternal factors have to be considered as determinants of low stature. The height of mothers of the study population is not known, but mothers' height of the 1974-76 cohorts of the same community is known. The median was $158.7 \mathrm{~cm}$, indicating lower stature in comparison with a sample of Caucasian US women of childbearing age (National Center for Health Statistics, 1976a). The reference population is from a middle class community of Ohio, where studies of secular trends have shown that the children had attained their maximum growth potential (National Center for Health Statistics, 1977). Our study population is heterogeneous in several important respects-namely, social class, ethnic group, and length of residence in Israel. We can assume that they have not yet reached their maximum growth potential. In a subsequent paper the effects on growth of ethnic, social, and cultural backgrounds will be discussed.

We thank Mrs. R. Elishkowsky-Halevi, the chief nurse of the mother and child health clinics, Mrs. $T$. Oren, and Professor M. Nichaman.

Analysis of the data was carried out with the help of a grant (No. 493 for 1977) from the Chief Scientist of the Ministry of Health of Israel.

Reprints from: Dr. Hava Palti, Department of Social Medicine, Hadassah Medical Organisation, POB 1172, Jerusalem, Israel.

\section{References}

Falkner, F. (1960). The somatic investigation. In Modern Problems in Pediatrics, volume 5, pp. 70-86. Edited by F. Falkner. Karger: Basel and New York.

Handlesman, Y., and Davies, A. M. (1975). Birth weight in Israel. Journal of Biosocial Science, 7, 153-164.

Kark, S. L., Peritz, E., Shiloh, A., and Slome, C. (1964). Epidemiologic analysis of the haemoglobin picture in parturient women of Jerusalem. American Journal of Public Health, 54, 947-960.

Kark, S. L. (1974). A community program for promotion of growth and development. In Epidemiology and Community Medicine, pp. 415-463. Appleton Century Crofts: New York.

Monto, A. S., and Ullman, E. M. (1974). Acute respiratory illness in an American community. The Tecumseh Study. Journal of the American Medical Association, 227, 164-169.

National Center for Health Statistics (1976a). Height and weight of adults 18-74 years of age in the United States. US Department of Health, Education and Welfare: Washington DC.

National Center for Health Statistics (1976b). NCHS Growth Charts, volume 25, Supplement No. 3. US Department of Health, Education and Welfare: Washington DC.

National Center for Health Statistics (1977). Growth curves for children from birth-18 years United States. Series 11, No. 165. US Department of Health, Education and Welfare: Washington DC.

Nichaman, Z. M., and Reshef, A. (1978). Attained growth status of selected groups of Israeli children. American Journal of Clinical Nutrition, 31, 895-903.

Palti, H., and Adler, B. (1977). Body size of Israeli newborn infants in relation to regional origin of their mothers. Human Biology, 49, 41-50. 
Palti, H., Adler, B., and Reshef, A. (1977). A semilongitudinal study of food intake, anemia rate and body measurements of 6-24 month-old children in a Jerusalem community. American Journal of Clinical Nutrition, 30, 268-274.

Palti, H., Zloto, R., and Gampel, B. (1979). Infection rate and anaemia in infancy in a family practice. Israel Journal of Medical Sciences, 15, 165-167.

Shiloh, A., and Yekutiel, M. (1958). Weights and heights of Israeli children. Acta Medica Orientalia, 13, 18-23.

Sveger, T., Lindberg, T., Weibull, B., and Olsson, L. (1975). Nutrition, overnutrition and obesity in the first year of life in Malmo, Sweden. Acta Paediatrica Scandinavica, 64, 635-642.
Taitz, L. S. (1971). Infantile overnutrition in artificially fed infants in the Sheffield region. British Medical Journal, 1, 315-316.

Waterlow, J. C., Buzina, R., Keller, W., Lane, J. M. Nichaman, M. Z., and Tanner, J. M. (1977). The presentation and use of height and weight data for comparing the nutritional status of groups of children under 10 years. Bulletin of the World Health Organisation, 55, 489-498.

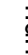
作 